\title{
A SOCIOLOGIA CONFIGURACIONAL DE NORBERT ELIAS - POTENCIALIDADES E CONTRIBUIÇÕES PARA O ESTUDO DO ESPORTE
}

\author{
MS. JULIANO DE SOUZA \\ Departamento de Educação Física, Setor de Ciências da Saúde, \\ Universidade Estadual do Centro-Oeste \\ (Guarapuava - Paraná - Brasil) \\ E-mail: julianoedf@yahoo.com.br
}

\section{DR. FERNANDO AUGUSTO STAREPRAVO}

Departamento de Educação Física, Centro de Ciências da Saúde, Universidade Estadual de Maringá

(Maringá - Paraná - Brasil)

E-mail: fernando.starepravo@hotmail.com

\section{DR. WANDERLEY MARCHI JÚNIOR}

Departamento de Educação Física, Setor de Ciências Biológicas,

Universidade Federal do Paraná

(Curitiba - Paraná - Brasil)

E-mail:marchijr@ufpr.br

\section{RESUMO}

\begin{abstract}
Neste artigo procuramos avaliar algumas contribuições bem como potencialidades teórico- metodológicas da abordagem sociológica de Norbert Elias no que diz respeito à delimitação do esporte como objeto relevante de pesquisa, e que pode nos ajudar a entender um pouco mais sobre o comportamento dos seres humanos em termos do redirecionamento da economia emocional que tem preponderado em sociedades mais diferenciadas como as nossas de hoje. Na primeira parte do texto procuramos apresentar em linhas bastante gerais, de que maneira o esporte veio a ser concebido por Elias como um problema sociológico. Já na segunda parte, temos por principal intuito argumentar que alguns aspectos da abordagem eliasiana criticados por Dias (20 l 0), em texto publicado nesse mesmo periódico, ao invés de se constituírem como reservas para uma adequada tematização do fenômeno esportivo, tratam-se, outrossim, das principais contribuições do modelo de Elias para o estudo sociológico do esporte.
\end{abstract}

PALAVRAS-CHAVE: Sociologia; esporte; lazer; Norbert Elias. 
Se eu fosse livre de escolher o meu mundo, provavelmente não teria escolhido uma humanidade onde as lutas entre seres humanos são consideradas excitantes e agradáveis. E não teria por certo escolhido apresentá-lo através de uma teoria. Teria talvez optado por dizer: evitem a luta. Vamos viver em paz. Mas acontece que, enquanto cientista, não posso apresentar o mundo tal como eu gostaria que ele fosse. Não sou livre para apresentar de outra maneira para além daquela que descobri. E descobri que os seres humanos, tal como eu os posso observar, para além da excitação agradável do sexo, também necessitam de outras formas de excitamento deleitante, sendo a excitação da luta uma delas, e que, na nossa sociedade, quando se atingiu um nível razoavelmente elevado de pacificação, esse problema foi até certo ponto resolvido pela provisão de confrontos miméticos, confrontos realizados por meio do jogo num contexto que pode originar uma excitação agradável, desencadeada pelo combate, com o mínimo de ferimentos nos seres humanos.

Norbert Elias (In: A busca da excitação)

\section{INTRODUÇÃO}

Ao nos depararmos com a leitura do artigo "A Sociologia Figuracional e os Estudos do Esporte" publicado em 2010 na edição n. 2, volume 3 I da Revista Brasileira de Ciências do Esporte pelo pesquisador Cleber Dias, de fato, ficamos um tanto quanto surpreendidos com algumas das críticas imputadas no texto à obra do sociólogo alemão Norbert Elias, bem como à atuação científica dos estudiosos do esporte que partilham desse referencial e se constituem, portanto, como divulgadores/difusores das ideias do pensador alemão.

Essa surpresa, no entanto, foi menos com os argumentos apresentados que remontam, diga-se de passagem, a uma espécie de jargões que vem se tornando rotineiros em razão, sobretudo, de disputas por prestígio e poder no campo das Ciências Humanas e Sociais e no próprio campo da Educação Física e mais com a possibilidade de refletirmos, a partir das ideias desenvolvidas no texto, sobre o processo de apropriação do referencial teórico de Elias no âmbito dos estudos histórico-sociológicos do esporte no Brasil.

Como é de conhecimento, a circulação dos escritos eliasianos no Brasil é algo um tanto quanto recente. $\bigcirc$ primeiro texto aqui traduzido, a título de reforço dessa argumentação, foi o volume n. I da obra "O processo civilizador" (ELIAS, 1990), em projeto encabeçado pela Editora Jorge Zahar no ano de 1990. Também os primeiros congressos e mesas temáticas dedicadas ao estudo aprofundado da obra do autor alemão são recentes no Brasil. Citamos, nesse propósito, a mesa redonda intitulada "Norbert Elias: 100 anos" que contou com a participação de importantes sociólogos brasileiros (Heloisa Pontes, Federico Neiburg, Leopold Waizbort, Jessé 
Souza) e que foi apresentada na XXI Reunião da ANPOCS (Associação Nacional de Pós-Graduação e Pesquisa em Ciências Sociais) em 1997, na cidade de Caxambu. Vale notarmos que os textos que compuseram a referida mesa resultaram, com o acréscimo de um manuscrito de Sergio Miceli que, por sinal, havia sido disponibilizado aos quatro demais sociólogos no evento, na produção do "Dossiê Norbert Elias" organizado em 1999 por Leopold Waizbort (WAIZBORT, 1999).

Outra iniciativa bastante expressiva e decisiva, especialmente para constituiçã̃o de um campo de estudos relativamente autônomo da Sociologia do Esporte no Brasil, ${ }^{1}$ foi a criação do Simpósio Internacional Processo Civilizador graças aos esforços do historiador Ademir Gebara e, é claro, de uma série de outros estudiosos e pesquisadores. A primeira edição do evento, a saber, foi realizada em 1996 na cidade de Campinas e contou com a presença de um dos mais renomados divulgadores da obra de Norbert Elias em escala internacional, qual seja, o sociólogo inglês Eric Dunning. Nas demais edições do evento, vários outros importantes estudiosos da obra de Elias como, por exemplo, Johan Goudsblom, Stephen Mennell e Cas Wouters participaram na condição de conferencistas, contribuindo de maneira determinante para com a divulgação e circulação do pensamento eliasiano no Brasil e na América do Sul.

No entanto, devemos reiterar que apesar dessas iniciativas acadêmicas rapidamente evocadas serem significativas no que se refere à introdução dos textos de Elias no Brasil, a circulação da obra eliasiana no país ainda é precoce e incipiente, o que, por sua vez, nos conduz ao entendimento de que a apropriação dos conceitos, ideias e do próprio método do autor ainda está em processo. E diríamos mais, direcionando a leitura para nossa área de atuação: não apenas a obra de Elias está em fase de apropriação no campo acadêmico-científico da Educação Física no Brasil, mas também a obra de Pierre Bourdieu, de Michel Foucault, dos teóricos da Escola de Frankfurt, sem falar de autores clássicos da Sociologia como Max Weber, Émile Durkheim, George Simmel, Karl Mannheim e, especialmente, Karl Marx, que passa a ter seus escritos revisitados de uma forma menos enviesada e política.

Sem dúvida, essa precocidade na apropriação teórica dos referenciais sociológicos no campo acadêmico-científico da Educação Física brasileira, torna o exercício da crítica uma tarefa de elevado grau de dificuldade no interior do referido campo,

I. Entendemos a Sociologia do Esporte no Brasil como um campo de tensões/solidariedades próprio que possui uma história específica definida por sua cronologia, suas leis, seus agentes e seus objetos de disputa. Outra particularidade desse campo é o fato de o mesmo ser marcado pela interdisciplinaridade quando senão pela transdisciplinaridade, até porque no seu interior concorrem/solidarizam pesquisadores e pesquisadoras das mais diferentes áreas de conhecimento, disputando os mesmos espaços editoriais, frequentando os mesmos eventos e, acima de tudo, divergindo (mas, por vezes, convergindo) quando à própria definição do que vem a ser a Sociologia do Esporte e quanto às agendas de pesquisa a serem desenvolvidas. 
especialmente em se tratando da análise da obra de um autor cujo empreendimento sociológico é de extrema envergadura e relevância para as Ciências Humanas e Sociais. Um bom exemplo disso que estamos dizendo poderia ser recuperado ao revisitarmos, a partir de uma leitura criteriosa, o já referenciado texto de Dias (20 I 0), visto que o mesmo talvez seja sintomático, quando senão uma tentativa de sistematização de críticas rotinizadas no campo acadêmico à obra eliasiana.

$\mathrm{Na}$ esteira dessa discussão aberta, é que procuramos, portanto, ao longo do presente artigo, avaliar algumas contribuições bem como potencialidades da abordagem sociológica de Elias no que diz respeito à delimitação do esporte como objeto relevante de pesquisa, e que pode nos ajudar a entender um pouco mais sobre o comportamento dos seres humanos em termos do redirecionamento da economia emocional que tem preponderado em sociedades mais diferenciadas como as nossas de hoje. Deste modo, nas linhas que seguem temos por objetivo principal apresentar alguns dos aspectos que julgamos centrais no trabalho de Elias em se tratando da constituição de um programa de pesquisa em Sociologia do Esporte.

A estratégia definida para exposição de nosso argumento consiste na articulação de dois momentos bastante específicos. Na primeira parte do artigo procuramos então apresentar, em linhas gerais, de que maneira o esporte veio a ser concebido por Elias como um problema sociológico. Já na segunda parte do texto, temos por principal intuito argumentar que aqueles aspectos da abordagem eliasiana criticados por Dias (2010), ao invés de se constituírem como "reservas" para uma adequada tematização do fenômeno esportivo, tratam-se das principais potencialidades e contribuições metodológicas do modelo eliasiano para o estudo sociológico do esporte. Antes, porém, de avançarmos nesse desiderato, importa reconhecermos que todo exercício de permitir-se discordar não pode ser cego e insensível ao respeito que devemos ter pelos pares no campo. Nesse caso, ao nos reportarmos aos posicionamentos de Dias (2010) não somos tomados por essa cegueira e insensibilidade.

\section{NASCE UM PROGRAMA DE PESQUISA - O ESPORTE NA ÓTICA ELIASIANA}

O primeiro e, talvez, mais importante texto de Norbert Elias versando sobre a temática do esporte - A dinâmica dos grupos desportivos: uma referência especial ao futebol - foi publicado em 1966 no British Journal of Sociology (ELIAS; DUNNING, 1966) com a colaboração de Eric Dunning que, a essas alturas, já havia defendido sua tese de mestrado sob a orientação do próprio Elias em 196I (DUNNING, |961). No citado artigo, os autores procuraram discutir a dinâmica dos grupos esportivos - mais especificamente no que diz respeito aos desdobramentos dessa 
dinâmica no futebol - sob o crivo de argumentos já desenvolvidos em "O processo civilizador" e no conhecido artigo sobre os modelos de jogos (ELIAS, 1980) que Elias escrevera enquanto orientava Dunning no mestrado.

O grande mérito dos autores nesse texto, sem dúvida, foi terem desenvolvido a noção de conflito e consenso como polaridades interdependentes. Ao constatarem, por exemplo, que a dinâmica de um jogo de futebol não se constituía por conta de um conjunto de regras entendidas como exteriores aos indivíduos, mas, pelo contrário, como uma configuração própria de equipes e indivíduos, Elias e Dunning ( 1 992a) puderam avançar consideravelmente na compreensão de que eram as tensões controladas entre as duas equipes no interior da configuração que compunham que, de fato, os mantinha em equilíbrio entre si.

Nesse caso, quando se diz que o esporte fornece um clímax onde predomina um descontrole controlado dos afetos e pulsões, na verdade está se dizendo, em outras palavras, que as noções de conflito e consenso no âmbito dos estudos configuracionais do esporte não podem ser tratadas como dimensões isoladas e estanques. Essa abordagem, no entanto, não se restringe apenas à esfera esportiva, e se constitui como uma contribuição legada à teoria social contemporânea por Elias e Dunning através de um objeto de estudo que estava se constituindo e sendo trazido para as agendas sociológicas, ou seja, o esporte.

Em 1969, um segundo texto, tão importante quanto o primeiro e que tem como título "A busca da excitação no lazer", foi publicado por Norbert Elias em Society and Leisure: Bulletin for Sociology of Leisure, Education and Culture. De acordo com Eric Dunning ( 1992) esse texto, bem como o anterior, contém elementos teórico-metodológicos de muita importância, e é neles que Elias e ele próprio avançam, pela primeira vez, no sentido de elaboração de uma teoria sociológica mais geral do esporte e do lazer. Essa versão do artigo publicado em Society and Leisure tratava-se de uma edição revisada da comunicação "The quest for excitement in unexciting societies" proferida em 1967 na conferência anual da British Sociological Association em Londres (ELIAS; DUNNING, 1992b, p. I0I).

Nesse texto, os autores esboçam uma tipologia preliminar para pensar a estruturação do tempo livre, de modo a demonstrar que apenas uma parcela desse tempo é destinada, de fato, ao lazer. Nitidamente os argumentos de Elias e Dunning ( I 992b) se desenvolvem no sentido de elucidar a insuficiência das abordagens, seja em nível teórico ou então prático, que encaram as noções de tempo livre e lazer mais ou menos como sinônimos. Além disso, só por esse aspecto já se poderia justificar o motivo pelo qual a oposição trabalho versus lazer é inadequada e deletéria para o propósito de se avançar em uma compreensão mais integradora e alargada da vida humana, ainda mais se considerarmos o fato de que, no âmbito da hierarquia 
moral da sociedade e, inclusive, de algumas interpretações sociológicas produzidas sobre a temática, o lazer é visto como uma atividade dominada pelo prazer, e o trabalho, por sua vez, como uma atividade revestida de seriedade e compromisso.

Em contrapartida a essas leituras fragmentárias e reducionistas do mundo social, Elias e Dunning ( 1992) ponderam e argumentam que nas sociedades mais diferenciadas do nosso tempo e, mais que isso, em sociedades relativamente pacificadas onde, na larga escala de tempo, avançou-se de uma condição pré-científica para uma condição mais científica de produção de conhecimento sobre a vida humana em suas variadas dimensões (ELIAS, 1998), as fronteiras entre as atividades de lazer e de não-lazer são tênues, de modo que se torna embaraçado e dificultoso decidir se "[...] os trabalhos de jardinagem de um professor, devem ser classificados como trabalho, ou a prática de um jogador de futebol profissional ser considerado como lazer" (ELIAS; DUNNING, 1992b, p. 107).

Como alternativa a esse problema, a Sociologia Configuracional nos oferece uma perspectiva de apreciação sociológica das relações entre o lazer e o não-lazer a partir de uma sofisticada teoria das emoções, justamente por se entender que existe uma relação de interdependência entre os sentimentos vivenciados pelos seres humanos nas chamadas relações "sérias" da vida e em seus momentos de lazer. Nesse caso, e em resposta aquelas hipóteses construídas sobre o lazer em termos de "libertação das tensões" ou "recuperação do desgaste do trabalho", argumenta-se em favor do entendimento de que as pessoas procuram na esfera mimética do lazer uma espécie de excitação agradável de certo modo complementar às restrições impostas nas rotinas diárias. Nos próprios termos de Elias e Dunning:

\footnotetext{
A estimulação emocional peculiar e a renovação de energias proporcionada pelas actividades de lazer da categoria mimética, culminando numa tensão agradável, representam um equivalente mais ou menos institucionalizado face ao poder e à uniformidade das restrições emocionais exigidas por todos os tipos de acções intencionais dos indivíduos nas sociedades mais diferenciadas e civilizadas. A agradável excitação-prazer que as pessoas procuram nas suas horas de lazer, representa assim, ao mesmo tempo, o complemento e a antítese da tendência habitual perante a banalidade das valências emocionais que se deparam nas premeditadas rotinas "racionais" da vida (ELIAS; DUNNING, I 992b, p. I I 5).
}

Com base nessa argumentação, novamente é possível notar o desenvolvimento das noções de conflito e consenso como polos interdependentes, haja vista que os indivíduos em suas atividades de lazer, assim como nas chamadas relações "sérias" e rotineiras da vida, também se organizam segundo o equilíbrio emocional das tensões. A grande diferença, nesse caso, é que nas atividades de lazer as tensões que os indivíduos procuram são de uma natureza relativamente diferente 
daquelas que evocam no tempo de não-lazer, de modo que é correto afirmar, em conformidade com Elias e Dunning (1 992b), que em uma sociedade cada vez mais diferenciada, onde as inclinações para as "excitações sérias" e de tipo ameaçador diminuíram, a função compensadora da "excitação-jogo" aumentou.

Importa sublinhar, inclusive, que foi justamente com o propósito de dar conta dessa arquitetura teórica, que Elias e Dunning recorreram a dois conceitos-chave desenvolvidos na tradição filosófica aristotélica, quais sejam, as noções de catarse e mimesis. Rapidamente falando, a apropriação que esses autores fazem do conceito de catarse, tal como empregada por Aristóteles ao pensar na música e na tragédia, se dá no sentido de abordar os esportes e as demais práticas de lazer como momentos que, em sentido figurado, permitem expulsar substâncias nocivas do corpo por meio de uma purga, ou melhor, que "[...] possuem um efeito curativo desencadeado não através dos intestinos, mas através de um movimento da alma" (ELIAS; DUNNING, I 992b, p. 122). Já o conceito de mimesis não se refere a uma simples imitação de situações da vida real por meio dos próprios fatos miméticos, mas, antes de tudo, que as próprias "[...] emoções - os sentimentos desencadeados por elas - estão relacionadas com as que se experimentam em situações da "vida real" transpostas apenas e combinadas com uma espécie de prazer" (ELIAS; DUNNING, 1992b, p. 125).

Conforme expresso nas palavras dos autores e no uso das categorias delimitadas, é possível então afirmarmos que essas são as duas noções centrais para o entendimento dos significados/funções sociais do esporte e das demais atividades de entretenimento e lazer nas sociedades modernas, tendo como ponto de sustentação a matriz teórica configuracional. Todavia, o que nos importa frisar, ao menos por enquanto, é que embora Elias tivesse se ocupado primeiramente do esporte e logo em seguida do lazer, até por conta da orientação da tese de mestrado de Dunning sobre futebol, uma das chaves centrais para leitura sociológica do esporte a partir de sua abordagem, é constituída quando circunscrevemos esse objeto no quadro metodológico mais amplo de preceitos que integram sua teoria geral do lazer.

Esse tipo de argumento é reforçado ao examinarmos a própria estrutura de organização da coletânea "A busca da excitação" publicada no inglês em 1986, quatro anos antes do falecimento de Elias, e da qual esses dois textos que aqui evocamos fazem parte. Os dois primeiros capítulos do livro tratam sobre lazer, e é neles que Elias sistematiza seu quadro teórico referente a essa temática. Vale notarmos que a ordenação dos capítulos que compõem o livro não foi estabelecida obedecendo à cronologia de escrita dos textos o que, por sua vez, nos leva a acreditar que a obra foi estruturada segundo critérios que favorecessem uma compreensão global e exata do desenvolvimento da teoria e do pensamento dos autores. 
Feitas essas contextualizações, é importante ressaltar, portanto, que do primeiro texto publicado por Elias em 1966 até a publicação dessa coletânea em 1986, contabiliza-se vinte e um anos de esforços dedicados pelo sociólogo alemão à Sociologia do Esporte e do Lazer, o que, diga-se de passagem, constitui um tempo de desenvolvimento intelectual considerável. Também devemos lembrar que o manifestado interesse de Elias pelo esporte, em parte, se fez devedor ao seu encontro com Eric Dunning, que decidiu trabalhar essa temática no mestrado, se bem que, segundo as palavras do próprio Dunning em entrevista concedida a Gebara (2005, p. 40), foi um colega dele, David Moscow, quem teve a ideia original, mas, na oportunidade, não conseguiu uma bolsa de estudos e, portanto, o financiamento para realizar a pesquisa.

Não obstante, Elias, se assim o desejasse e tivesse motivos, poderia ter abandonado a temática do esporte e do lazer logo após o término da orientação de mestrado de Dunning. Felizmente as coisas não ocorreram dessa forma. É sintomático também desse período - um momento em que o mundo ainda se reorganizava econômica e emocionalmente da Segunda Guerra - que o próprio Elias, segundo as observações de Garrigou (200 I), vinha recebendo algumas críticas acadêmicas de certa forma carregadas de ironia, e que basicamente indagavam sobre como ele se sentia após ver o processo civilizacional do ocidente europeu que havia descrito/estudado completamente encerrado. Em contrapartida, Elias, a essa altura, um intelectual septuagenário, respondia a tais críticas com redobrado trabalho, convencido, ao menos ele próprio (ELIAS, 200 la), da dimensão e relevância de seu empreendimento para a tradição sociológica e para compreensão holística e alargada da sociedade.

Esse contexto evocado, por conseguinte, é no mínimo revelador e nos permite tecer o comentário, não sem recorrer novamente a Garrigou (200 I ), que o interesse de Elias pelo esporte e pelo lazer consistiu basicamente em dar continuidade às reflexões empreendidas quando do estudo dos processos civilizadores ocidentais europeus, mais especificamente, tais como dimensionados na Alemanha, na França e na Inglaterra. Interessante também notarmos que o próprio reconhecimento acadêmico do trabalho de Elias ganhou crédito, especialmente na Alemanha e nos países falantes da língua inglesa, por conta dos estudos desenvolvidos sobre as práticas esportivas e sobre o lazer, conforme podemos inferir dos depoimentos de Eric Dunning e Johan Goudsblom concedidos a Gebara (2005, p. I 2 I - 122).

Até aqui procuramos fazer um breve recenseamento histórico de como surgiu e foi concebido o programa eliasiano para uma Sociologia do Esporte. Argumentamos de modo um tanto quanto ligeiro que uma das entradas possíveis para leitura do esporte pelo prisma da Sociologia Configuracional seria considerar esse fenômeno 
como circunscrito no quadro de preocupações empírico-teóricas mais amplas de Norbert Elias com o lazer e com o processo civilizador como um todo. A partir de agora, no entanto, iremos nos deter em alguns outros aspectos que, do ponto de vista teórico-metodológico, entendemos como centrais para se levar adiante a constituição de um programa de pesquisas histórico-sociológicas sobre o fenômeno esportivo à luz de alguns dos preceitos que integram a Sociologia Configuracional e, mais precisamente, a Teoria dos Processos.

\section{CONTRIBUIÇÕES ELIASIANAS PARA UMA SOCIOLOGIA DO ESPORTE}

Em conformidade com o que já foi dito na parte introdutória do texto, a estratégia que adotaremos para exposição daqueles aspectos que julgamos centrais de serem retidos do empreendimento sociológico de Elias, a fim de levarmos a efeito a leitura e interpretação do fenômeno esportivo moderno, consiste na retomada de algumas das críticas apresentadas no já mencionado texto do pesquisador Cleber Dias, ${ }^{2}$ até porque os desdobramentos da abordagem eliasiana colocados em xeque por tal investigador se constituem, no nosso entendimento e de modo diferente das ideias desenvolvidas no seu texto, como suportes teórico-metodológicos de suma importância e que figuram como possibilidades alternativas para procedermos no estudo do esporte a partir de um ponto de vista histórico-sociológico.

$\mathrm{Na}$ esteira desse empreendimento, julgamos oportuno recuperar já de imediato um dos objetivos centrais propostos por Dias (2010) no texto "A Sociologia Figuracional e os Estudos do Esporte", a saber, o de apresentar resumidamente as explicações da abordagem eliasiana para a gênese do esporte moderno. Importa frisarmos que, ao acompanharmos como foi sendo desenvolvido esse objetivo ao longo do texto, notamos que em nenhum momento Dias (20 l 0) teve a preocupação de se referir ao fato do esporte moderno ser um fenômeno que surgiu primeiramente na Inglaterra. Vale frisar que quando Norbert Elias, num primeiro momento, fala de esporte moderno, ele está se referindo a um conjunto de processos que teve lugar primeiramente na sociedade inglesa da metade final do século XIX. Em

2. Gostaríamos de abordar outros aspectos desse texto como, por exemplo, sobre a temática do holocausto (p. 159-160), sobre a questão das tensões entre os estilos de vida modernos e tradicionais no esporte (p. 162-163) e, por fim, sobre a suposta negligência de Elias em relação à divisão das atividades de lazer tais como constituídas e dimensionadas segundo a lógica da estrutura de classes no interior de uma mesma sociedade (p. 163). No entanto, o espaço editorial reservado para o artigo não nos permitiu essas réplicas. Como sugestões de leituras para um melhor tratamento de tais polêmicas, ver respectivamente: ELIAS, N. O colapso da civilização. In: ELIAS, N. Os alemães - A luta pelo poder e a evolução do habitus nos séculos XIX e XX. Rio de Janeiro, Jorge Zahar, 1997, p. 267-355; ELIAS, N. Introdução. In: ELIAS, N.; DUNNING, E. A busca da excitação. Lisboa: Difel, I992, p. 39-99; ELIAS, N.; SCOTSON, J. L. Os estabelecidos e os outsiders: sociologia das relações de poder a partir de uma pequena comunidade. Rio de Janeiro: Jorge Zahar, 2000. 
termos bastante sintéticos, a problemática colocada por Elias se apresenta da seguinte forma: por que a sistematização das primeiras práticas esportivas tipicamente modernas se deu primeiramente na Inglaterra e não na Alemanha, na França ou em outra sociedade qualquer, por exemplo?

Ao estudar a formação do parlamentarismo na Inglaterra, Norbert Elias apresenta alguns argumentos que nos permitem melhor entender a indagação colocada. Para o autor, o mesmo grupo social - um pequeno grupo de proprietários rurais desenvolvido no interior da aristocracia inglesa - que havia participado no avanço da pacificação e no aumento da regulamentação das lutas entre as facções no parlamento inglês, também contribuiu para o aumento da pacificação e regularização de seus divertimentos (ELIAS, 1992). Tal processo, por sua vez, foi expresso objetivamente, dentre outros fatores, na criação dos clubes, das associações e, nas décadas seguintes, das primeiras confederações esportivas.

Em contrapartida, um pequeno grupo de proprietários rurais não poderia ter se desenvolvido e se sustentado no interior do círculo aristocrático francês e alemão, porque tanto na Alemanha quanto na França, a posse de terras estava estritamente relacionada à tradição feudal que ligava objetivamente o monopólio de grandes propriedades rurais a serviços de guerras prestados ao soberano. Além disso, a posse de terras nesses países era uma exclusividade dos nobres, exatamente pelo fato de tal atributo conferir e estabelecer o senso de distinção que permitia a esse grupo se diferenciar dos demais. Por sua vez, na Inglaterra essa tensão já havia sido quase que completamente diluída nas teias de interdependências sociais ao longo dos séculos XVIII e XIX (ELIAS, 1993).

Decorre dessa leitura a conclusão de que a "esportivização" dos passatempos ingleses no âmbito do lazer corresponde ao movimento civilizatório verificado empiricamente na estrutura política inglesa por conta da criação do parlamento, até porque os mesmos homens que faziam as leis ou então iam à igreja, como bem alerta Elias (1992), eram também os que impunham regras aos antigos jogos populares estabelecendo, na esteira de longo prazo, um significado diferenciado para essas práticas. Acresça-se a essa análise, o fato desses processos serem característicos da mesma modificação na estrutura do poder na Inglaterra e nos hábitos sociais dessa pequena "aristocracia rural", que se consolidou como grupo com relativo poder nas tomadas de decisões. Em suma, a condição de aparecimento dos primeiros esportes modernos e das primeiras competições esportivas modernas na Inglaterra se deve, sobretudo, ao fato dessa sociedade ter reunido e acumulado as condições que, contempladas de um ponto de vista psicogenético e sociogenético, eram necessárias para que o desenvolvimento dessas práticas esportivas de caráter regulamentado fosse efetivamente possível. 
Esse tipo de compreensão, decorrente da sensibilidade comparativa de Norbert Elias entre as três sociedades europeias que se dedicou com mais afinco em sua obra, faz toda a diferença em seu empreendimento sociológico no sentido de, num primeiro momento, poder mapear as regularidades dos processos sociais estudados em ambos os países e, numa etapa seguinte, estabelecer as especificidades da direção do processo civilizador dos costumes em relação à constituição de cada um dos Estados europeus delimitados, algo bastante explícito na última parte do volume dois de "O processo civilizador" (ELIAS, 1993). Sendo assim, é no mínimo estranho o fato do pesquisador Cleber Dias (2010) não ter mencionado esse aspecto em seu texto. Muitas de suas pretensas críticas, nesse sentido, poderiam ser repensadas ou até mesmo evitadas caso essa observação metodológica fosse feita.

Um segundo ponto polêmico a ser retomado do texto de Dias (20l0) diz respeito às conjecturas tecidas sobre o suposto etnocentrismo ou eurocentrismo de Elias - considerações desenvolvidas no referido artigo tomando como núcleo argumentativo aquelas experiências que foram acumuladas pelo sociólogo alemão enquanto residira em Gana (DIAS, 20 I 0, p. 16I). Como alternativa a tal argumentação, frisamos, entretanto, que o conhecimento, por um lado, sobre a perspectiva comparativa eliasiana e, por outro, sobre a necessidade e importância de delimitação de objetos empíricos que o pesquisador tenha um envolvimento pessoal e as devidas doses de enraizamento com o locus de estudo que açambarca o objeto eleito, amenizaria as interpretações e talvez a recorrência constante às críticas pontuais de alguns comentadores no sentido de rotular Elias como etnocêntrico ou eurocêntrico.

Não obstante essas ressalvas apresentadas, importa reconhecermos que Elias, de fato, tinha um profundo interesse sobre a cultura alemã, francesa e inglesa, resultante, sobretudo, do fato de ter residido, por ordem dos acontecimentos desenrolados na estrutura social mais ampla e em sua própria vida, nos três países. Sabemos que ainda residindo na Alemanha, mais especificamente durante o período de 1930 a 1933 na cidade de Frankfurt, Elias já havia trabalhado sobre o século XVIII francês e escrito a primeira versão de "A sociedade de corte" (ELIAS, 200 l b). Soma-se, além disso, a esse prognóstico, o fato de que suas experiências vivenciadas na França entre 1933 e 1935, acrescidas de seu elevado conhecimento sobre a cultura alemã e sobre a sociedade inglesa que passara a residir em 1935, foram decisivos para que redigisse em três anos, não sem recorrer ao método comparado e também a insights de suas observações e vivências acumuladas in loco nos referidos países, o seu principal texto, "O processo civilizador", publicado pela primeira vez em 1939 na cidade de Basileia/Suíça.

Colocado sob outro aparato terminológico, o que queremos dizer ou chamar atenção com esse breve recenseamento, mais especificamente, é que o 
conhecimento aprofundado/ incorporado sobre determinadas realidades a serem estudadas trata-se de uma condição sine qua non para o desenvolvimento da pesquisa sociológica tal como entende Norbert Elias. Essa qualidade, somada ao método de distanciamento, vem a fundar uma condição teórica e prática ideal para efetivação da ciência sociológica conformando, por sua vez, o exercício metodológico que Elias ( 1998 ) veio a chamar de "envolvimento distanciado".

Deste modo, o fato de Elias ter preterido o processo civilizador chinês ou então norte-americano em função do processo civilizador francês, alemão e inglês, não se trata de uma questão de eurocentrismo ou etnocentrismo, mas, primeiramente, de uma opção metodológica central de sua Teoria das Configurações e dos Processos e, segundo, de um limite geográfico e linguístico imposto ao autor, pois se tivesse nascido na Ásia ao invés da Europa as coisas poderiam ter tomado outros rumos. Todavia, esse quadro não é tão desanimador e existe um vastíssimo campo aberto para investigação dos processos civilizadores tais como (re) dimensionados na China (STEBBINS, 2009), nos Estados Unidos (MENNELL, 2007) e no Brasil (LUCENA, 2000; BRANDÃO, 2007), para ficarmos com apenas três exemplos.

Um terceiro e último ponto que gostaríamos de recuperar do texto de Dias (20।0), e que nos remete por indução à leitura da forma como Elias concebe as relações entre teoria e empiria e entre as dimensões micro e macrossociológicas, está expresso no seguinte trecho:

A idéia insistentemente repetida por Elias e pelos eliasianos de que é preciso efetivar uma pesquisa empírica guiada por uma teoria expõe uma forma de conceber o trabalho sociológico que é bastante discutível, pois, partindo aprioristicamente de um modelo que, em última instância, deve ser confirmado, não é difícil transformar o trabalho de pesquisa em um mero esforço de reunir evidencias ao seu favor (DIAS, 2010 , p. 164, grifos nossos).

Antes, porém, de comentarmos sobre a proposta eliasiana elaborada no intuito de se rever as polarizações estéreis estabelecidas entre teoria e empiria e entre as dimensões do microcosmo e do macrocosmo social, é importante frisar que os argumentos de Dias contidos nesse fragmento não fazem jus ao exercício de apropriação que os leitores mais atentos de Norbert Elias no Brasil têm feito dos preceitos metodológicos que açambarcam e integram esse referencial teórico. Assim sendo, entendemos que tal crítica carece de um maior respaldo e aprofundamento nos escritos do próprio Elias, de modo a não encaminhar a réplica no sentido de reprodução de argumentos fundados em perigosos sistemas de crenças acadêmicas. Nesse caso e com o propósito de lançar luz a tais interpretações, julgamos importante fazer alguns breves esclarecimentos sobre a Teoria do Processo Civilizador.

De acordo com Norbert Elias, não existe o "grau zero" da civilização, como tampouco um ponto em que os atos bárbaros foram suprimidos e a vida civilizada 
começou (ELIAS, 1992). Sua abordagem se dá em termos de um processo histórico não-planejado, ou seja, não intencional, mas que, apesar disso, obedece a uma lógica estrutural ordenada e que ao mesmo tempo é diferente de algo que é linear, ou melhor, que se estabelece em apenas uma direção (ELIAS, 2006). Isso é tão verdade que Elias reconhece em várias oportunidades de sua obra que todas as tendências de civilização são acompanhadas pelas tendências de descivilização, embora, devamos reconhecer que, em termos do longo curso, a primeira tendência foi a mais recorrente ou, em outros termos, a mais bem-sucedida na constituição da sociedade moderna.

Além disso, uma leitura mais cuidadosa da obra de Elias daria conta de recuperar um importante insight teórico-metodológico repetido em inúmeras oportunidades pelo sociólogo alemão, qual seja, o de que o sentido e a direção dos ajustes e desajustes civilizatórios e descivilizatórios é algo sempre em aberto, isto é, que precisa ser revelado e descortinado mediante um rigoroso trabalho empírico. Dessa forma, quando Elias nos cobra a importância de desenvolvermos trabalhos empíricos teoricamente direcionados, ele, em outras palavras, está advogando em favor de que procuremos estabelecer tendências paralelas entre processos micro e macrossociológicos de desenvolvimento das sociedades humanas, observando a dimensão de longo prazo, as rupturas e mudanças históricas, assim como o movimento pendular da balança de poder em sua relação com o nível de autocontrole emocional e de domínio dos afetos de grupos de observação empírica da sociedade.

Acresça-se a essa forma de compreensão que o resgate, por via do trabalho empírico, dessas tendências paralelas e sob o crivo da Teoria do Processo Civilizador, bem como a demonstração da natureza de direção e ajuste das mesmas nos fornece um mapa teórico, ou melhor, um modelo heurístico, para superar a tensão micro-macrossociológica tão recorrente no campo das Ciências Sociais, até mesmo por conta da divisão do trabalho intelectual, que é a própria divisão estruturada entre disciplinas, áreas de conhecimento e especialidades.

Bons exemplos dessas tendências paralelas seria a constatação empírica de que a estrutura de emergência do comportamento civilizado está diretamente relacionada com a organização das sociedades europeias ocidentais, sobre a forma de Estados (ELIAS, 1990; 1993); de que a tragédia pessoal de Mozart tem relações com a estrutura de funcionamento dos campos artísticos europeus nas sociedades de corte (ELIAS, 1995); de que o grande colapso da civilização, que culminou com uma das cenas mais cruéis da história, a saber, o holocausto, tem relações diretas com o curso de desenvolvimento de uma autoimagem fragmentada da Alemanha (ELIAS, 1997); de que a gênese do esporte moderno estaria relacionada com a estrutura de composição do regime parlamentar inglês (ELIAS, 1992). 
Com base nesse conjunto de argumentações, podemos dizer, portanto, que o que Dias (20 I 0) está entendendo por estudos empíricos teoricamente direcionados é um tanto quanto diferente do que Elias sistematizou a respeito desse procedimento ao longo de mais de cinquenta anos de contribuição legada à Sociologia. Talvez esse tipo de leitura seja fruto, como mencionamos já mesmo na introdução do artigo, de um processo ainda incipiente de apropriação do referencial de Elias no campo acadêmico-científico da Educação Física no Brasil e no campo da Sociologia do Esporte, com suas devidas e destacadas exceções, é claro.

\section{CONSIDERAÇÕES FINAIS}

Estudos dos esportes que não tenham por pretensão serem igualmente estudos das sociedades em que essas mesmas práticas esportivas estão inseridas se constituem em explicações sociológicas, de certa forma, insuficientes para o entendimento rigoroso dos significados, funções e papéis que o esporte cumpre em formações sociais tão diferenciadas quanto as que conhecemos. Essa, sem dúvida alguma, é a grande lição que podemos reter do empreendimento sociológico de Norbert Elias e Eric Dunning em se tratando da constituição de um programa científico para Sociologia do Esporte.

Mas os méritos não se limitam ao acima dito e, como pudemos perceber em nossa intervenção feita no decorrer deste artigo, a Sociologia Configuracional que vai ser buscada por Elias na Teoria do Processo Civilizador se constitui em uma abordagem adequada e fecunda para procedermos no tratamento das complexas tensões estabelecidas entre pesquisador e objeto, entre teoria e empiria, entre indivíduo e sociedade, entre microcosmo e macrocosmo social, entre o aparato psicossocial individualizado e as relações de poder no contexto das interdependências.

Em contrapartida, vimos no texto do pesquisador Cleber Dias (2010) aqui adotado a título de interlocução crítica, uma série de argumentos que, por vezes, remetem a uma concepção metodológica de pesquisa sociológica que, de certo modo, reporta a uma suposta condição de rigidez entre as fronteiras de três áreas do saber que tem procurado trazer o esporte e lazer para a agenda de pesquisas acadêmicas, isto é, a Sociologia, a Antropologia e a História. No entanto, e em conformidade com a abordagem eliasiana, somos levados a crer que as fronteiras entre as três áreas não são tão rígidas quanto parecem, embora devamos reconhecer que o caráter de cientificidade para o tratamento de um objeto como o esporte não está na eleição das melhores fontes que supostamente conteriam as verdades "prontas" sobre o mundo social, e nem muito menos em descrições subjetivas que, por mais belíssimas que sejam, revelam muito pouco sobre o funcionamento da 
sociedade e sobre a complexificação da vida com todos seus dilemas e ocultamentos que escapam à consciência dos atores.

Nesse particular, podemos dizer que Dias (20 I0), pela forma como constrói sua crítica aos estudos configuracionais, parece se enveredar ligeiramente pelo método de pesquisa na qual a incursão empírica antecede qualquer observação teórica mais sistemática, de modo que o pesquisador deve sair a campo "aparentemente" desarmado de noções operatórias e modelos de análise, com a melhor das intenções, é claro, de coletar ou produzir uma informação "neutra". Não obstante, para rompermos com as evidências do conhecimento imediato e com as surpresas enganosas que o universo dos esportes reserva, devemo-nos pautar em modelos teóricos gerativos e relacionais pensados para guiar a pesquisa empírica e superar a oposição infundada entre teoria e empiria - o modelo de Elias é exemplar, nesse sentido.

À guisa de fechamento, reiteramos que as contribuições de Elias e Dunning para a Sociologia do Esporte se apresentam tanto em termos de sistematização de uma teoria geral do esporte e do lazer, quanto na tentativa certeira e devidamente reconhecida de trazer um objeto aparentemente fútil e indigno para a hierarquia dos objetos de pesquisa em Ciências Sociais, de modo que não é nenhum exagero dizer que, ao menos no Brasil, o campo da Sociologia do Esporte, por conta da incorporação do referencial teórico-metodológico em questão e desse modus operandi, tem suas devidas dívidas - uma gentil forma de prestar homenagem - em termos de seu desenvolvimento recente para com esses autores.

A par desta condição, cabe a nós pesquisadores que concorremos/interagimos no campo acadêmico-científico da Educação Física no Brasil, dedicar um maior tempo e esforço na apropriação do suporte teórico-metodológico que integra a Teoria dos Processos e das Configurações, de forma que possamos superar alguns problemas relativos à produção de conhecimento da área e, sobretudo, na Sociologia do Esporte e do Lazer.

\section{The Figurational Sociology of Norbert Elias - Potentialities and Contributions to the Study of Sport}

ABSTRACT: In this paper we evaluate some contributions as well as theoretical and methodological potentialities of Norbert Elias' sociology approach. We emphasize his concern about the delimitation of sports as a relevant object of research that can help us to have a better understanding about human behavior. Specifically, the human behavior is understood in terms of emotional economy redirection that has more prevalence in different societies, such as ours nowadays. In the first section, we present very general lines of how the sport came to be conceived by Elias as a sociological problem. In the second part, we have a main purpose to argue that some aspects of the Eliasian approach criticized by Dias (2010), in 
a text published in this journal, rather than as reserves to constitute an adequate theme of the sport phenomenon, these are, likewise, the main contributions of the model of Elias to the sociological study of sport.

KEYWORDS: Sociology; Sports; Leisure; Norbert Elias.

\section{La sociología figuracional de Norbert Elias - potencialidades y contribuciones para el estudio del deporte}

RESUMEN: En este trabajo se evalúa algunas de las contribuciones, así como las potencialidades teóricas y metodológicas de la sociología de Norbert Elias sobre la delimitación del deporte como relevante objeto de investigación que pueden ayudarnos a entender más sobre el comportamiento humano en términos de reorientación de la economía emocional que tiene mayor prevalencia en las diferentes sociedades como la nuestra hoy. En el primer apartado, se presentan las líneas muy generales de cómo el deporte llegó a ser concebido por Elias como un problema sociológico. En la segunda parte, tenemos como objetivo principal argumentar que algunos aspectos del enfoque de Elias criticado por Dias (2010), en un texto publicado en esa misma revista, en lugar de las reservas para constituir un problematización adecuada del fenómeno deportivo, se trata, del mismo modo, las principales aportaciones del modelo de Elías para el estudio sociológico del deporte.

PALABRAS CLAVE: La sociología; deporte; ocio; Norbert Elias.

\section{REFERÊNCIAS}

BRANDÃO, C. F. Os processos de civilização e o controle das emoções. Bauru/SP: EDUSC, 2007.

DIAS, C. A sociologia figuracional e os estudos do esporte. Revista Brasileira de Ciências do Esporte, Campinas, v. 31 , n. 2, p. 155-169, jan. 2010.

DUNNING, E. Early stages in the development of Football as in organized game. Master Thesis. University of Leicester, Leicester, 1961.

ELIAS, N. Modelos de Jogo. In: ELIAS, N. Introdução à Sociologia. Lisboa: Edições 70, 1980 , p. $77-112$.

. O processo civilizador - uma história dos costumes. (v. I). Rio de Janeiro: Zahar, 1990. 1992, p. 39-99.

. Introdução. In: ELIAS, N.; DUNNING, E. A busca da excitação. Lisboa: Difel,

. O processo civilizador - formação do estado e civilização (v. 2). Rio de Janeiro: Zahar, 1993.

- Mozart - Sociologia de um gênio. Rio de Janeiro, Jorge Zahar, 1995.

. $O$ colapso da civilização. In: . Os alemães - A luta pelo poder e a evolução do habitus nos séculos XIX e XX. Rio de Janeiro, Jorge Zahar, I997, p. 267-355.

. Envolvimento e alienação. Rio de Janeiro: Bertrand Brasil, 1998. 
. Norbert Elias por ele mesmo. Rio de Janeiro, Jorge Zahar, $200 \mathrm{I}$ a.

ELIAS, N. A sociedade de corte. Rio de Janeiro, Jorge Zahar, $200 \mathrm{lb}$.

. Para a fundamentação de uma teoria dos processos sociais. In: . Escritos \&

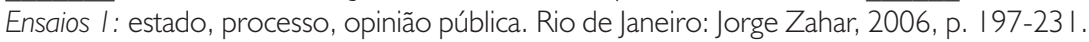

ELIAS, N.; DUNNING, E. Dynamics of sport groups with special reference to football. British Journal of Sociology, London, v. 17, n. 3, p. 388-402, dez. 1966.

. Quest for excitement: sport and leisure in the civilizing process. Oxford: Basil Blackwell, 1986.

. A dinâmica dos grupos esportivos - uma referência especial ao futebol. In: ELIAS, N.; DUNNING, E. A busca da excitação. Lisboa: Difel, 1992a, p. 279-297.

. A busca da excitação no lazer. In: ELIAS, N.; DUNNING, E. A busca da excitação. Lisboa: Difel, 1992b, p. 101-138.

ELIAS, N.; SCOTSON, J. L. Os estabelecidos e os outsiders: sociologia das relações de poder a partir de uma pequena comunidade. Rio de Janeiro: Jorge Zahar, 2000.

GARRIGOU, A. O "grande jogo" da sociedade. In: GARRIGOU, A.; LACROIX, B. (orgs.). Norbert Elias: a política e a história. São Paulo: Editora Perspectiva, 200 I , p. 65-88.

GEBARA, A. Conversas sobre Norbert Elias: depoimentos para história do pensamento sociológico. 2. ed. Piracicaba/SP: Biscalchin Editor, 2005.

LUCENA, R. F. O esporte na cidade: aspectos do esforço civilizador brasileiro. I39f. Tese (Doutorado em Educação Física) - Universidade de Campinas, Campinas, 2000.

MENNELL, S. The american civilizing process. Cambridge: Polity Press, 2007.

STEBBINS, A. The chinese civilizing process: eliasian thought as an effective analytical tool for the chinese cultural context. 386f. Thesis (PHD in Philosophy) - University of Murdock, Perth/ Australia, 2009.

WAIZBORT, L. (org.). Dossiê Norbert Elias. São Paulo: EDUSP, 1999.

Recebido em: | 4 abr. 20 I I Aprovado em: 10 set. 2011

Endereço para correspondência: Juliano de Souza

Departamento de Educação Física Rua Simeão Camargo Varella de Sá, 03

Campus Cedeteg

Guarapuava-PR 
